\title{
Introduction to special issue: Rail transit development in China and beyond
}

\section{Mi Diao}

Institute of Real Estate and Urban Studies

National University of Singapore

diaomi@nus.edu.sg

\section{Xueliang Zhang}

School of Urban and Regional Science

Shanghai University of Finance and

Economics

\author{
Yingling Fan \\ Humphrey School of Public Affairs \\ University of Minnesota
}

Rail transit is widely considered an efficient and environment-friendly means to address the increasing demand for travel. In the past decades, the scale and speed of China's rail transit development has been unprecedented. By the end of 2017, a total of 165 urban rail lines including heavy rail and light rail were in operation in 34 cities in mainland China, with a total track length of 5,033 kilometers $(\mathrm{km})$; the vast majority of them were built after 2000 (China Association of Metros, 2017). At the intercity scale, China has built the largest high-speed rail (HSR) network in the world, with over 29,000 km of HSR lines by the end of 2018 (Central Government of China, 2019). Efforts to develop rail transit are also observed in other cities in both developing and developed countries.

Rail transit drastically reduces travel time and cost within and between cities. By improving interand intracity accessibility, rail transit investment in China and other countries not only has a direct impact on travel patterns, but also could affect urban development and economic growth. Understanding the impact of rail transit investment has significant implications for appropriate policy adaptions to direct future growth trajectories and mitigate potential negative effects of urban expansion.

We planned this special issue in response to the rapid development of rail transit in China and beyond. In preparation for the special issue, we organized two symposiums to facilitate debates on related research topics in June 2017: A special session on rail transit at the 11th annual conference of the International Association for China Planning (IACP) hosted by the Harbin Institute of Technology in Harbin, China, and the second Symposium on the HSR Network in China hosted by Jinan University in Guangzhou, China. Both events were chaired by the editors of the special issue, with support from the IACP organization. In the end, we received a total of 18 papers. After the standard peer-review process, we accepted 8 papers for the special issue, with 7 of them focusing on rail transit in China and 1 focusing on light rail in a US context. The special issue also has a well-balanced research focus on different types of rail transit systems, with 5 papers on urban rail transit and 3 on the HSR in China.

Urban rail transit is a key component of urban transport systems. It is generally agreed that urban rail transit could bring a variety of benefits to the neighboring areas by improving accessibility. Two papers in the special issue assess the housing price appreciation resulting from urban rail transit, adding new evidence to the long thread of literature on this topic. Guan and Peiser (2018) apply principal component analysis (PCA) to a set of neighborhood built-environment characteristics and access to Metro station variables and subsequently integrate the factors produced by the PCA into OLS hedonic price

Copyright 2019 Mi Diao, Yingling Fan, \& Xueliang Zhang

http://dx.doi.org/10.5198/jtlu.2019.1571

ISSN: 1938-7849 | Licensed under the Creative Commons Attribution - Noncommercial License 4.0

The Journal of Transport and Land Use is the official journal of the World Society for Transport and Land Use (WSTLUR) and is published and sponsored by the University of Minnesota Center for Transportation Studies. 
models. They find that the metro system has a positive influence on housing prices in Pudong, Shanghai. Pan (2019) calibrates OLS, multi-level regression, and spatial econometric models to investigate the impact of a light rail line - the METRORail in Houston — on residential property values and finds a significant positive effect. The benefit of urban rail transit is reflected not only in housing price premiums, but also in changes in human sentiments. Using a micro survey dataset of Shanghai in 2013, Li et al. (2018) find proximity to a subway station increases self-reported rating of happiness at the individual level after accounting for residential self-section.

Despite the various benefits brought by urban rail transit, high cost and low ridership remain two major barriers for rail transit development. Zhao et al. (2018) use ridership and investment data of 109 urban rail lines in 28 Chinese cities to understand factors that could influence the performance and cost effectiveness of urban rail transit systems. They find that land use density, project design, system service, and multimodal transit integration play important roles in projecting ridership, thus affecting the cost effectiveness and success of rail transit projects. One key characteristic of successful rail transit systems is the existence of high-quality Transit-Served Areas (TSAs) along rail lines. Based on 167 TSAs in Shenzhen, China, Zhou et al. (2018) illustrate how to combine nontraditional data such as social media and mobile phone data and traditional data such as interviews and censuses to evaluate physical features and performance of TSAs. They argue that nontraditional data could contribute to improving the performance of rail transit systems by offering a new lens to understand and monitor TSAs.

Three papers in the special issue focus on the HSR system in China. Among them, two papers examine the role of HSR for intercity passenger mobility at the regional and metropolitan scales, respectively. Using the Chengdu-Chongqing Passenger Dedicated Line as a case study, Ren et al. (2019) assess the impact of HSR on intercity travel behavior changes. They show that HSR has become the primary mode of intercity travel and led to substantial increases in travel demand between Chengdu and Chongqing. Thus, the economic linkage between these two major cities in the region has been strengthened. Lin et al. (2018) examine the feasibility of using national HSR services for intercity passenger mobility between the central city and the periphery in the Shenzhen-Dongguan-Huizhou Metropolitan Area. They show that HSR is competitive at the metropolitan scale and discuss the institutional factors related to such arrangement. The two papers provide new evidence on the role of HSR in enhancing connectivity at different spatial scales. The HSR-induced connectivity gain could foster economic growth. To test this hypothesis, Chong et al. (2019) apply spatial econometric modeling techniques to a panel dataset for 268 Chinese cities from 2008 to 2015. Their findings confirm that the connectivity improvement brought by HSR has a positive effect on GDP per capita at the city level.

With a wide range of topics covered by the eight high-quality papers, we hope that this special issue will provide useful insights for the ongoing rail transit boom in China and contribute to the research efforts on rail transit around the globe. 


\section{References}

Central Government of China. (2019). Witnessing China's High-Speed Rail Development. Retrieved from http://www.gov.cn/xinwen/2019-01/10/content_5356665.htm

China Association of Metros. (2017). Annual statistical report 2017. Retrieved from http://www.camet. org.cn/index.php? $\mathrm{m}=$ content $\& \mathrm{c}=$ index $\& \mathrm{a}=$ show\&catid $=18 \& \mathrm{id}=13532$

Chong, Z., Qin, C., \& Chen, Z. (2019). Estimating the economic benefits of high-speed rail in China: A new perspective from the connectivity improvement. Journal of Transport and Land Use, 12(1): 287-302.

Guan, C., \& Peiser, R. (2018). Accessibility, urban form, and property value: A study of Pudong, Shanghai. Journal of Transport and Land Use, 11(1), 1057-1080.

Li, W., Sun, B., Yin, C., Zhang, T., \& Liu, Q. (2018). Does metro proximity promote happiness? Evidence from Shanghai. Journal of Transport and Land Use, 11(1), 1271-1285.

Lin, X., Yang, J., \& MacLachlan, I. (2018). High-speed rail as a solution to metropolitan passenger mobility: The case of Shenzhen-Dongguan-Huizhou metropolitan area. Journal of Transport and Land Use, 11(1), 1257-1270.

Pan, Q. (2019). The impacts of light rail on residential property values in a non-zoning city: A new test on the Houston METRORail transit line. Journal of Transport and Land Use, 12(1): 241-264.

Ren, X., Chen, Z., Wang, F., Wang, J., Wang, C., Dan, T., \& Du, Z. (2019). Impact of high-speed rail on intercity travel behavior change: The evidence from the Chengdu-Chongqing Passenger Dedicated Line. Journal of Transport and Land Use 12(1): 265-285.

Zhao, J., Li, C., Zhang, R., \& Palmer, M. (2018). Cost of an urban rail ride: A nation-level analysis of ridership, capital costs and cost-effectiveness performance of urban rail transit projects in China. Journal of Transport and Land Use, 11(1), 1173-1191.

Zhou, J., Wang, Q., \& Liu, H. (2018). Evaluating transit-served areas with non-traditional data: An exploratory study of Shenzhen, China. Journal of Transport and Land Use, 11(1), 1323-1349. 